\section{Ethnoracial disparity among patients with dementia during COVID-19 pandemic}

\section{Disparidade étnico-racial entre pacientes com demência durante a pandemia da COVID-19}

\author{
Disparidad étnico-racial entre pacientes con \\ demencia durante la pandemia de COVID-19
}

\author{
Natan Feter 1,2 \\ Jayne Santos Leite 3 \\ Ricardo Alt 1 \\ Airton José Rombaldi 1
}

\begin{abstract}
We aim to examine the effect of the COVID-19 pandemic on the ethnoracial disparities in hospitalizations due to dementia and its related outcomes, in Brazil. A longitudinal panel study was carried out with data extracted from the Hospital Information Systems of the Brazilian Unified National Health System (SIH/SUS). We assessed the number of hospital admission per 100,000 inhabitants, mean inpatient spending, and inpatient mortality rate due to dementia during the first semester of 2019 and 2020. Data were stratified by geographic region and ethnoracial groups (black, mixed, and white) based on skin color. We observed an overall reduction in hospital admissions, mean inpatient spending, and mortality rate between the first semester of 2019 and 2020. However, the reduction of hospitalization rates among black and mixed people was $105.3 \%$ and $121.1 \%$ greater than in whites, respectively. Mortality rate was decreased by $9 \%$ in whites and was increased by $65 \%$ and $43 \%$ in the black and mixed population, respectively. In the first semester of 2020, black and mixed patients had a higher risk of losing their lives due to dementia than white people. This disparity was not observed in the same period of 2019. In 2020, the inpatient mortality ratio reached the highest values among black individuals in all regions but the North (no data available). Since the beginning of the COVID-19 epidemic in Brazil, ethnoracial disparity in hospital admissions and mortality rates due to dementia has been heightened. Governmental actions and policies to mitigate this indirect effect of the pandemic on the Brazilian population are urgent.
\end{abstract}

Ethnicity; Dementia; COVID-19

\author{
Correspondence \\ N. Feter \\ Universidade Federal de Pelotas. \\ Rua Luís de Camões 625, Pelotas, RS 96055-630, Brasil. \\ natanfeter@hotmail.com \\ 1 Universidade Federal de Pelotas, Pelotas, Brasil. \\ 2 The University of Queensland, St. Lucia, Australia. \\ 3 Universidade Federal do Rio Grande do Sul, Porto Alegre, \\ Brasil.
}




\section{Introduction}

Although Brazil had the second-highest age-standardized prevalence of dementia in the world in 20161, disparities in the burden of dementia, especially in vulnerable populations, have been reported 2. Recent decades have witnessed an increase of black and mixed (i.e., pardo) population in Brazil 3. From 2012 to 2018 the number of people who self-declared themselves as black increased roughly $32.2 \%$, reaching 19.2 million 3 . Although the difference in the prevalence of dementia among ethnic and racial (hereafter called ethnoracial) groups remains controversial, previous studies have confirmed the ethnoracial and social disparity of dementia in countries such as the United States 4,5, Australia 6 , the United Kingdom 7, and Brazil 8,9. Inequity in access to health care, cultural beliefs of dementia as a part of normal aging, and lack of awareness about risk factors and treatment are some factors that might explain such disparity 10,11. For example, recent findings reported that two out of three people worldwide believe that there is little to no understanding of dementia in their countries 10 .

The absence of well-coordinated public policies to increase awareness about dementia has led to heightened prevalence, hospitalizations, and mortality rates worldwide, especially in low- and middle-income countries 1. In Brazil, hospitalizations from any type of dementia increased by $88 \%$ from 2010 to 2019. For comparison, highly prevalent chronic diseases, such as ischemic heart disease (29.3\%) and cerebrovascular disease (35.3\%), had a lower increase in hospital admission during the same 10-year period. Similarly, the expenditure with those admissions has increased in the last decade according to data from the Brazilian Health Informatics Department (DATASUS; http:// tabnet.datasus.gov.br/cgi/menu_tabnet_php.htm, accessed on 29/Apr/2021). The economic burden of hospitalizations due to dementia were increased by $43.8 \%$; for hospitalizations due to ischemic heart disease the increase was $34.5 \%$.

The ethnoracial disparity in the treatment, diagnosis, and progression of dementia in Brazil is also present 6 . Some factors - such as perceptions of the normal cognitive decline across ageing 12 , insurance coverage, access to health care 6 , and lifelong stress due to health vulnerability 13 - seem to explain these differences. Even so, from the sixteen countries in the world that have a dementia plan, one-third do not have equity as a principle of the action plan (World Health Organization. https:// apps.who.int/gho/data/node.dementia, accessed on 29/Apr/2021). Furthermore, the COVID-19 pandemic has disrupted the already unequal access to medical assistance and disease treatment, especially for vulnerable populations 14,15. Due to social distancing restrictions, telemedicine has been suggested as an alternative approach to maintain disease treatment during the pandemic ${ }^{16}$. However, the lack of access to virtual medical appointments and medications through delivery systems in some ethnoracial groups may compromise disease treatment, ultimately leading to hospital admissions and deaths 15,17 . Given the already elevated and unequal burden of dementia in Brazil, we aim to examine the effect of the COVID-19 pandemic in ethnoracial disparities on hospitalizations and related outcomes due to dementia in the country.

\section{Methods}

In this retrospective, longitudinal panel study, data of the Hospital Information Systems of the Brazilian Unified National Health System (SIH/SUS) from the first semester of 2019 and 2020 was analyzed. Data were accessed and extracted on October 8 th, 2020. Those periods were chosen to compare the situation before (2019) and during the peak of the first wave of the COVID-19 pandemic in Brazil (2020) 18. The total number of hospitalizations, mean paid or refunded value per hospital admission, and the inpatient mortality rate due to dementia were extracted and stratified by skin color (white, black, mixed, yellow) and geographic region (Central-West, North, Northeast, South, Southeast). Data regarding the number of hospitalizations among all ethnoracial groups and mortality rate among black patients from the North region were unavailable. Due to the lack of data about the yellow group in some outcomes, the values presented were from the white, black, and mixed categories. No restrictions on patients' age were adopted.

Hospitalization rates were reported as hospitalizations per 100,000 inhabitants. It was calculated by dividing the total hospital admissions by the population size according to the latest national 
survey 19 and multiplied by 100,000. Total inpatient spending was estimated as the sum of the paid or refunded values from all hospital admissions related to dementia, including hospital and professional services. Mean inpatient spending per hospitalization was estimated by dividing the total inpatient spending by the number of hospitalizations, in each period. Mortality rate was estimated as the proportion of inpatient deaths by the number of hospitalizations each year. Inpatient deaths were estimated as the number of hospitalizations with death as the discharged reason. The cause of hospitalization was informed as the main diagnosis, defined as what caused it according to the International Classification of Disease, 10th Revision (ICD-10) 20. For dementia, we considered all hospitalizations from which the main diagnosis was defined as Alzheimer's disease (ICD-10: F00; G30), vascular dementia (ICD-10: F01), dementia in other disease classified elsewhere (ICD-10: F02), and unspecified dementia (ICD-10: F03).

\section{Statistical analyses}

Continuous data were reported as absolute values, since the study extracted the total number of inpatient spending of hospitalizations and inpatient deaths, from both periods. One-way analysis of variance with Bonferroni's post-hoc was carried out to examine differences in hospitalization rate, mean inpatient spending, and mortality rate across regions. Changes between 2019 and 2020 were reported as percentages. Odds ratios for death during hospitalization were calculated by ethnoracial groups in each year. For that, we considered the number of hospitalizations and inpatient deaths in each group. All statistical analyses were performed using Stata 13.1 (https://www.stata.com). The level of significance was 0.05 .

\section{Results}

During the first semester of 2019 a total of 2,272 hospitalizations due to dementia in Brazil were recorded. In the same period of 2020, this number decreased 19.5\%, reaching 1,829 hospitalizations. The hospitalization rate decreased from 0.011 in 2019 to 0.007 , in 2020, in the overall population; as consequence, a reduction of 43\% in the mean inpatient spending was observed (2019: BRL 2,222.52; 2020: BRL 1,275.89). Interestedly, the expected decrease in inpatient mortality due to lower hospitalization number and inpatient spending was not seen (2019: 15.1\%; 2020: 15\%). As illustrated in Figure 1a, the decrease in hospital admissions was more pronounced among mixed (-42\%) and black $(-39 \%)$ individuals. The mean inpatient spending related to these hospitalizations was $56 \%$ lower in the black population in 2020 than in 2019 . A remarkable increase in mortality rate among black (65\%) and mixed (43\%) was followed by a decrease (-9\%) among whites.

Figure $1 \mathrm{~b}$ illustrates the odds ratio for inpatient mortality due to dementia by ethnoracial groups. Our findings indicate that in 2019 mixed patients had a lower risk of death than white counterparts during hospitalization. One year later, both black $(1.79 ; 95 \%$ CI: $1.12,2.86)$ and mixed $(1.61 ; 95 \%$ CI: $1.20,2.18)$ patients with dementia reported a heightened risk of mortality compared to white patients. No statistically significant difference was observed between black and mixed patients in both periods.

Table 1 describes the hospitalization rate, mean inpatient spending per hospital admission, and inpatient mortality rate by geographic regions and ethnoracial groups. The reduction by $32.2 \%$ in hospitalization rate in the Southeast region offsets the difference observed between this region with the North and Northeast in 2019. Likewise, the Southeast region had the highest mean inpatient spending, in 2020, compared to other regions. Also, in 2019 the Central-West and Southeast regions had the leading inpatient mortality rate due to dementia in the country. Nevertheless, the remarkable increase of this indicator placed the Northeast region (134.1\%) with the second-highest mortality rate in the country, with Central-West persisting in the first even after a slight decrease (-9.5\%).

Hospitalization rates decreased in most ethnoracial groups in the Northeast and Southeast regions. In the South, black (108.9\%) and white (19.7\%) people were more hospitalized between the two periods whereas the rate decreased among mixed (-25\%). Interestingly, while the overall number of hospitalizations per 100,000 inhabitants decreased in the country (Figure 1a; -31\%), the mean inpatient spending for each hospital admission increased in all regions. Moreover, the overall inpatient 


\section{Figure 1}

Changes in hospital admissions, mean inpatient spending, and inpatient mortality rate; and inpatient mortality rate by ethnoracial groups in the first semester of 2019 and 2020 in Brazil.

1a) Changes in hospital admissions, mean inpatient spending, and inpatient mortality rate

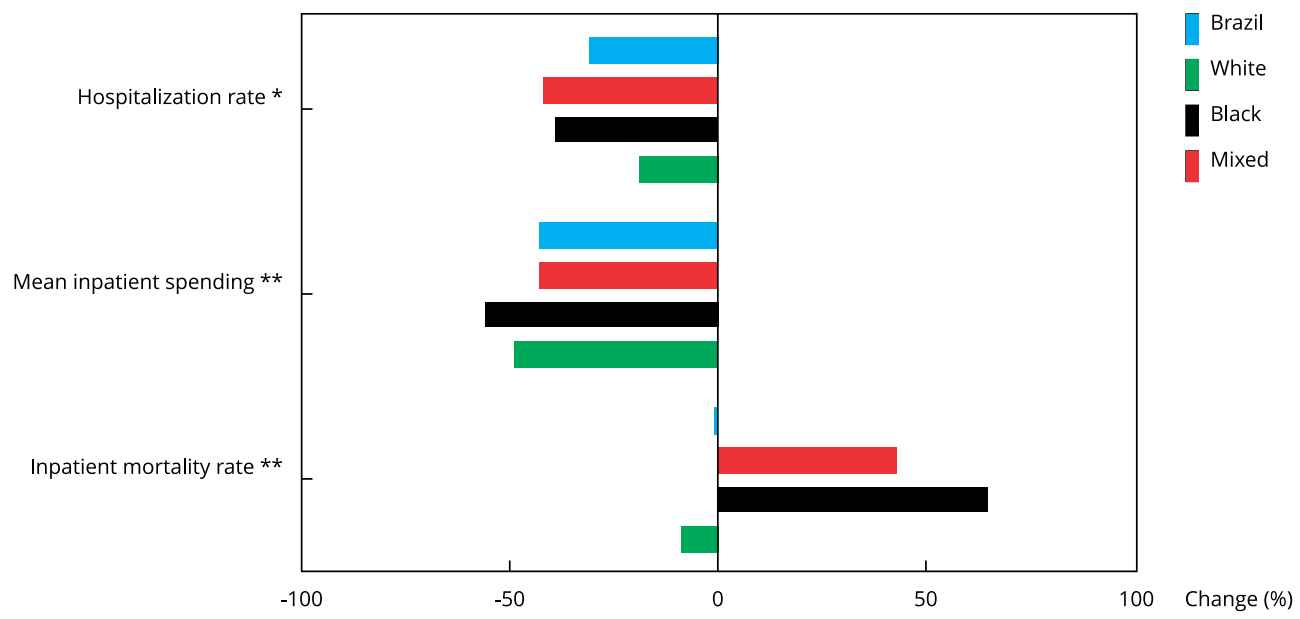

1b) Inpatient mortality rate by ethnoracial groups

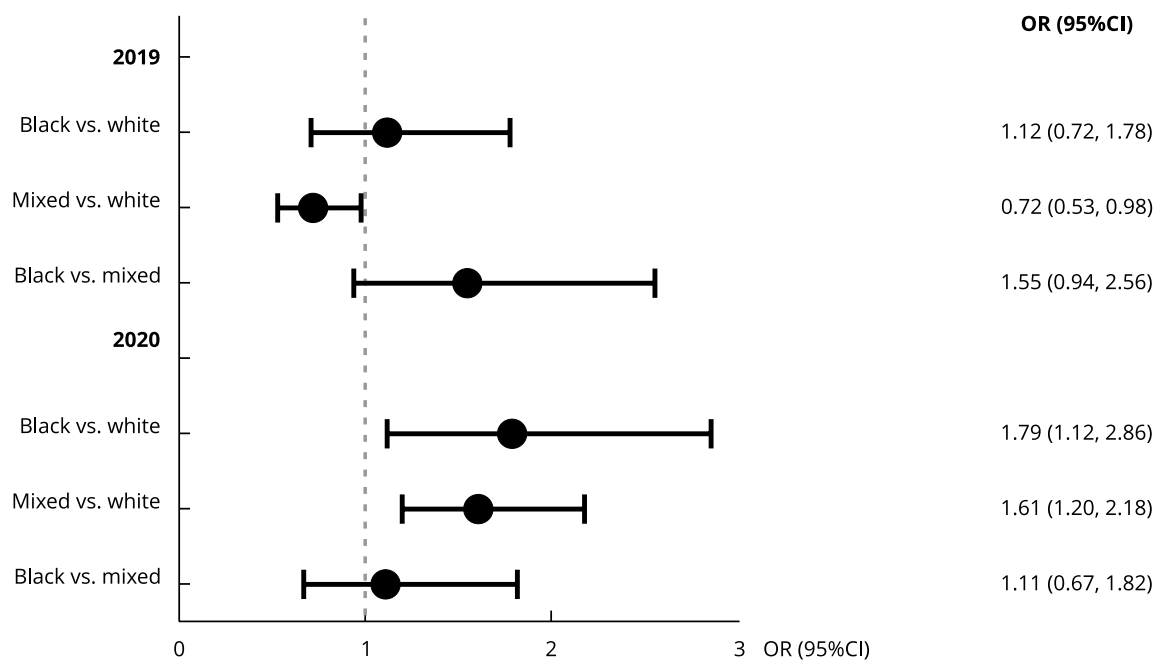

95\% Cl: 95\% confidence interval; OR: odds ratio.

* Per 100,00 inhabitants;

** Per hospitalizations. 
Table 1

Hospitalization rate, mean inpatient spending from each hospital admission, and inpatient mortality rate by region and ethnoracial group, in first semester of 2019 and 2020. Brazil, 2020.

\begin{tabular}{|c|c|c|c|c|c|c|c|c|c|c|c|c|}
\hline & \multicolumn{3}{|c|}{ Overall } & \multicolumn{3}{|c|}{ White } & \multicolumn{3}{|c|}{ Black } & \multicolumn{3}{|c|}{ Mixed } \\
\hline & 2019 & 2020 & $\%$ * & 2019 & 2020 & $\%$ * & 2019 & 2020 & $\%$ * & 2019 & 2020 & $\%$ * \\
\hline \multicolumn{13}{|c|}{ Hospitalization rate ** } \\
\hline \multicolumn{13}{|l|}{ Region } \\
\hline North & $0.28 * * *$ & 0.18 & -35.7 & 0.09 & 0.12 & 33.3 & N/A \# & - & - & 0.20 & 0.12 & -40.0 \\
\hline Northeast & $0.47 * \star \star$ & 0.41 & -12.8 & 0.22 & 0.14 & -36.4 & 0.28 & 0.24 & -14.3 & 0.33 & 0.36 & 9.1 \\
\hline Southeast & 1.52 & 1.03 & -32.2 & 1.32 & 1.03 & -22.0 & 1.18 & 0.71 & -39.8 & 0.91 & 0.05 & -94.5 \\
\hline South & 1.42 & 1.61 & 13.4 & 1.37 & 1.64 & 19.7 & 0.79 & 1.65 & 108.9 & 0.52 & 0.39 & -25.0 \\
\hline Central-West & 1.17 & 0.98 & -16.2 & 0.48 & 0.63 & 31.3 & 0.33 & 0.33 & 0.0 & 0.59 & 0.53 & -10.2 \\
\hline \multicolumn{13}{|c|}{ Mean inpatient spending (BRL 1,000$)$} \\
\hline \multicolumn{13}{|l|}{ Region } \\
\hline North & $0.56 \# \#$ & $0.63 \# \#$ & 12.5 & 0.41 & 0.23 & -43.9 & N/A \# & - & - & 0.93 & 1.04 & 11.8 \\
\hline Northeast & $1.75 \# \#$ & $2.08 \# \#$ & 18.9 & 2.09 & 2.46 & 17.7 & 4.45 & 6.20 & 39.3 & 1.62 & 1.84 & 13.6 \\
\hline Southeast & 5.86 & 7.85 & 34.0 & 6.60 & 7.67 & 16.2 & 8.21 & 11.53 & 40.4 & 7.84 & 14.40 & 83.7 \\
\hline South & $0.88 \# \#$ & $0.94 \# \#$ & 6.8 & 0.94 & 0.97 & 3.2 & 1.87 & 1.03 & -44.9 & 0.34 & 1.22 & 258.8 \\
\hline Central-West & 2.56 & $3.36 \# \#$ & 31.3 & 2.27 & 2.81 & 23.8 & 4.20 & 4.63 & 10.2 & 5.80 & 6.74 & 16.2 \\
\hline \multicolumn{13}{|c|}{ Inpatient mortality rate } \\
\hline \multicolumn{13}{|c|}{ Region } \\
\hline North \#\#\# & N/A & N/A & $\mathrm{N} / \mathrm{A}$ & N/A & $\mathrm{N} / \mathrm{A}$ & N/A & $\mathrm{N} / \mathrm{A}$ & $N / A$ & N/A & N/A & N/A & $N / A$ \\
\hline Northeast & 9.10 \#\# & 21.30 & 134.1 & 9.70 & 15.80 & 62.9 & 5.30 & 31.30 & 490.6 & 12.70 & 27.80 & 118.9 \\
\hline Southeast & 15.20 & 18.20 \#\# & 19.7 & 18.30 & 20.70 & 13.1 & 20.20 & 24.20 & 19.8 & 12.80 & 18.01 & 40.7 \\
\hline South & 9.80 \#\# & 9.40 \#\# & -4.1 & 10.30 & 8.33 & -19.1 & 9.10 & 17.40 & 91.2 & 2.90 & 8.00 & 175.9 \\
\hline Central-West & 36.80 & 33.30 & -9.5 & 50.00 & 36.10 & -27.8 & 40.00 & 60.00 & 50.0 & 21.60 & 42.50 & 96.8 \\
\hline
\end{tabular}

N/A: not available.

* Change in percentage from 2019 to 2020;

** Hospital admissions per 100,000 inhabitants;

*** $\mathrm{p}<0.05$ compared to Southeast region using on one-way ANOVA with Bonferroni's post hoc;

\# No data about hospitalization due to dementia and inpatient spending in black people at North region was available;

\#\# $\mathrm{p}<0.05$ compared to Central-West region using on one-way ANOVA with Bonferroni's post hoc;

\#\#\# No data about mortality rate due to dementia at North region by ethnoracial groups was available to compare periods.

mortality rate did not change meaningfully between the examined periods in the country $(-0.4 \%)$. Though the mortality rate diminished by $9 \%$ in white people, the proportion of inpatients who lost their lives in the hospital increased by $65 \%$ among black and $43 \%$ in the mixed population. Comparing the two periods, the inpatient mortality rate in 2020 was $19.1 \%$ and $27.8 \%$ lower than in 2019 among the white population in the South and Central-West regions, respectively. On the other hand, this rate increased by $91.2 \%$ and $50 \%$ in black and $175.9 \%$ and $96.8 \%$ in mixed populations, respectively in the South and Central-West regions. Even in regions, such as the Northeast, where the mortality rate increased in all ethnoracial groups, this change was heightened among black (490.6\%) and mixed (118.9\%) people compared to whites (62.9\%).

Moreover, Figure 2 illustrates the variation of hospitalization rates (2a), mean inpatient spending per hospital admission (2b), and inpatient mortality rate (2c) by ethnoracial groups and geographical regions between the first semester of 2019 and 2020. A decrease in hospitalization rates among black (-14.3\%) and white (-36.4\%) people followed by an increase in mixed (9.1\%) strengthening the inequality in the Northeast region. On the other hand, the disparity between white and black patients declined from 2019 to 2020 in the South and Central-West regions, with the mixed race population being less hospitalized during this period. White people were the ethnic group with the highest hospitalization rate in the Southeast and Central-West regions in the first semester of 2019 and 2020. 


\section{Figure 2}

Hospital admissions per 100,000 inhabitants, mean inpatient spending per hospitalization, and mortality rate per hospitalization across ethnoracial groups by geographic regions.

2a) Hospital admissions per 100,000 inhabitants

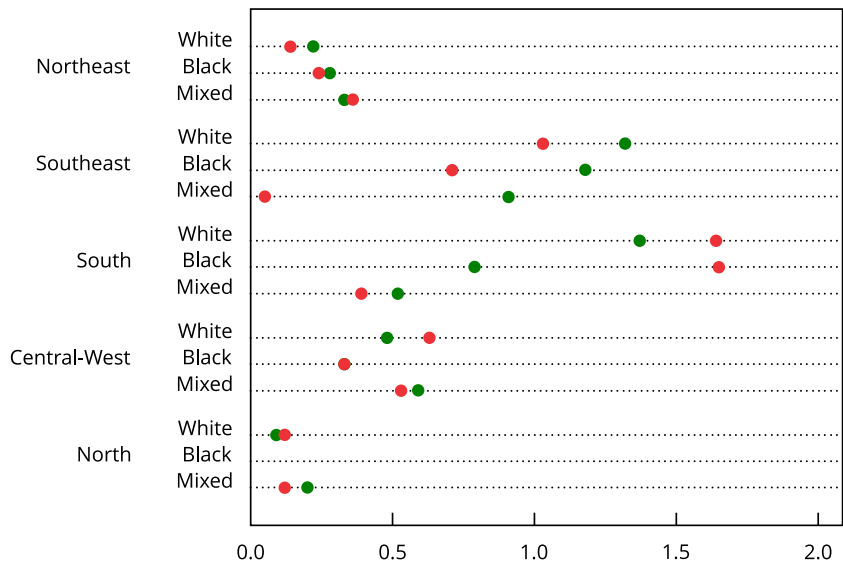

2020

2b) Mean inpatient spending per hospitalization

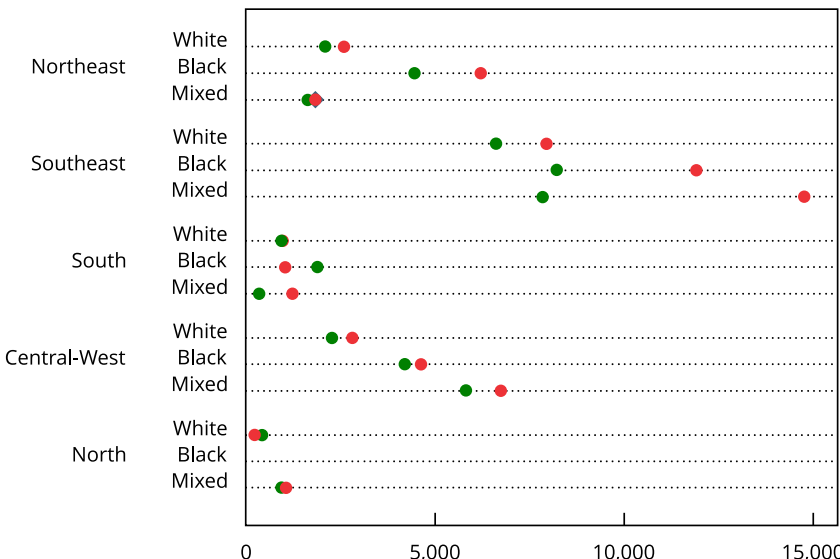

2019

2020

2c) Mortality rate per hospitalization

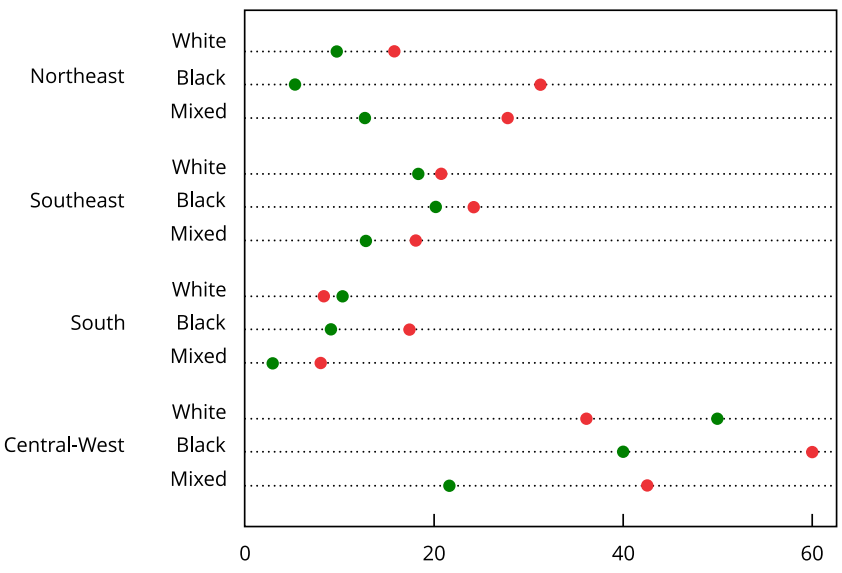

2019

2020

Inpatient mortality rate (\%) 
Decreased hospitalization rate in the Southeast region was followed by an increase in mean inpatient spending across all ethnoracial groups, as shown in Figure 2b. The difference in mean inpatient spending ranged from $18.8 \%$ (black vs. mixed) to $24.4 \%$ (black vs. whites) in 2019. Nevertheless, in 2020 , those values increased to $50.3 \%$ (black vs. whites) and $87.7 \%$ (mixed vs. whites). In the South region, the disparity in the inpatient spending was attenuated between the periods as a result of lower (-44.9\%) inpatient spending among black and higher inpatient spending (258.8\%) in the mixed population. No remarkable changes were observed across other regions regarding mean inpatient spending.

However, in 2020 the inpatient mortality ratio reached the highest values among black individuals in those regions, as shown in Figure 2c. In Central-West, white people had the highest mortality rate among all ethnic groups in 2019, dropping to the third position in 2020. A similar pattern was observed in the Northeast, where the mortality rate due to dementia raised by $490.6 \%$ among black Brazilians. As consequence, this ethnoracial group came from the third to the first position across groups while whites had the lowest rate in 2020 compared to the second-highest in 2019.

\section{Discussion}

We compared the ethnoracial disparities, before and during the COVID-19 pandemic in hospital admissions; inpatient spending; and mortality rate due to dementia in Brazil. We observed a reduction in hospital admissions and related inpatient spending between the first semester of 2019 and 2020, while the mortality rate increased in the same period. However, these indicators changed inversely across ethnoracial groups. Although a reduction in hospitalization rates was observed across all groups, the reduction among black and mixed people was, respectively, $105.3 \%$ and $121.1 \%$ greater than in whites. Also, the mortality rate was decreased by $9 \%$ in whites and increased by $65 \%$ and $43 \%$ in black and mixed populations, respectively. Furthermore, in the first semester of 2020, black and mixed patients had a higher risk of losing their lives due to dementia, when compared to white patients. This disparity was not observed in the same period of 2019.

The sudden rise in cases and deaths due to COVID-19 might explain the decrease in hospitalization rate from dementia, considering that age is a risk factor for both COVID-19 and dementia 21,22. However, the remarkable decrease of hospitalization rates in black and mixed subjects needs to be highlighted. The role genetics play in the race-specific difference, regarding the progression of dementia, seems to be overcome by cultural and social factors 5 . For example, the belief in dementia as a part of normal aging, differences in educational achievement, and inequity in access to health care may impact the diagnosis and treatment of such disease across ethnoracial groups. There is a need for culturally-specific studies that aim to understand the influence of cultural beliefs in the awareness of risk factors, diagnosis, progression, and treatment of dementia.

The study lead by Baqui et al. 21 showed that mixed and black ethnicity are the second and fourth most important risk factors for death by COVID-19 in Brazil, supporting the disparity observed in our findings. Although people with dementia are at higher risk of mortality by COVID-19, the same study showed that there was no significant difference in the prevalence of neurological diseases in COVID-19 patients among regions. Similarly, in the United States African-Americans with dementia are more likely to have COVID-19 infection than white patients 23 . Public health policies need to assure that people with dementia will have access to healthcare services during and after the pandemic regardless of skin color. In this vein, strategies to promote the diagnoses, treatment, and prevention of dementia must be sustained during social distancing. Otherwise, not only the burden of dementia might be heightened after - and during - the COVID-19 pandemic but also the ethnoracial disparity of such burden.

Black and Hispanic Americans are 2 and 1.5 times more likely to have Alzheimer's disease than non-Hispanic whites 24 . Previous research showed that this disparity may be related to genetic factors especially due to the higher proportion of African-Americans with APOE e4 compared to whites 25 . However, other modifiable factors such as the lack of knowledge about strategies to prevent or delay the onset of dementia symptoms may underpin the racial disparities in dementia prevalence and prognosis 26 . A recent worldwide survey about dementia awareness showed that for one in four people dementia is not preventable, and one-third believes dementia is part of normal ageing 10 . Although 
ethnicity seems to not be related to postdiagnosis survival time, the presence of cardiometabolic diseases such as hypertension and diabetes are linked to the heightened risk of mortality due to dementia 27. Likewise, older black and mixed adults are more likely to have a diagnosis of hypertension and diabetes, simultaneously, than whites, in Brazil 28. Thus, strategies to promote awareness and access to healthy lifestyles across ethnoracial groups must be developed to reduce the disparity in mortality due to dementia in Brazil.

Recently, the effect of lifelong stress due to health vulnerability on ethnoracial differences, in and progression of dementia has been strengthened 13. Cumulative exposure to stress, especially among the black and mixed population, has serious physiological consequences; such as increased vascular risk and white matter hyperintensities, both associated with the progression of dementia 13 . Due to the elevated prevalence of chronic comorbidities, these ethnoracial groups present the first signals of dementia when the disease is at more advanced stages. As consequence, they are more likely to require emergency services, which may be associated with the shorter duration of hospitalization and higher mortality rate. Moreover, the estimated proportion of patients with dementia treated with anticholinesterase drugs in 2014 was lower in the Northeast (5.8\%) and the North (2.6\%) region than the national average (16.1\%) 29. However, no data about the distribution of this critical pharmacological treatment by ethnoracial groups are available, raising the question about the coverage of governmental programs to distribute this medication among diverse ethnoracial groups.

We also observed that white patients had the lowest mean inpatient spending amongst ethnoracial groups. A report from the Alzheimer's Association (United States) described the total mean of Medicare payment for hospital care in white people as $40.6 \%$ and $31.2 \%$ lower than the observed in African-American and Hispanic, respectively 30. This increased inpatient spending might be attributable to higher levels of disabilities, associated with a higher prevalence of comorbidities and laterstage diagnosis. Inequalities in accessing primary care, diagnostic services, and awareness about the neurodegenerative process, associated with dementia, are related to delay in seeking health services. Furthermore, the absence of well-coordinated medical services might ultimately lead to duplication of services between providers, duplicating costs of hospital care, and increasing the likelihood of preventable hospitalizations, which is potentially avoidable with timely and effective ambulatory care. Data from the United States showed the proportion of this type of hospital admission is higher among Black and Hispanic Americans, with the highest proportion among Hispanic older adults 31. However, more investigations are necessary, especially in Brazil, to understand the reasons for this health disparity.

This study, however, has some limitations. First, the longitudinal panel design does not allow to delineate causal relationships between ethnoracial groups and hospitalization-related indicators. Second, the lack of data from other minorities such as Asian and Indigenous reduce our ability to extrapolate our findings to all ethnoracial groups in Brazil. For example, data about hospitalization rates in 2019 indicated that from the 2,272 hospitalizations in Brazil due to dementia, 26.8\% had no information about patients' ethnicity. The correct recording of the patients' demographic characteristics into hospitals' electronic systems is indispensable so public policies may be developed for ethnic minorities such as East Asian (i.e., yellow skin color) and indigenous population. Third, our analyses were based on data exclusively from the DATASUS. Data from hospitalizations in private hospitals not covered by the Brazilian Unified National Health System (SUS) may have not been accounted for in our analysis. Whilst approximately three-quarters of the Brazilian population seek public health care, private healthcare centers are more accessed by people in higher socioeconomic level 32 . This sampling bias is likely to underestimate our occurrence measurements in some groups including white patients in more developed regions. Four, the SIH/SUS accounted as "death" all hospitalizations with dementia as the main diagnosis, with death as the discharged reason. Therefore, it was not possible to determine whether a patient included in our analysis had COVID-19 or not.

In conclusion, ethnoracial disparity in hospital admissions and mortality rates due to dementia has increased since the beginning of the COVID-19 pandemic in Brazil. We expect our findings may be used for supporting governmental actions and policies to attenuate this indirect effect of the pandemic in the Brazilian population. 


\section{Contributors}

N. Feter conceived the concept and design of the study, participated in data analysis, written the manuscript, and provided substantial revision in all manuscript drafts. J. S. Leite conceived the concept and design of the study and provided substantial revision in all manuscript drafts. R. Alt participated in data analysis and provided substantial revision in all manuscript drafts. A. J. Rombaldi provided substantial revision in all manuscript drafts. All authors approved the final version of the manuscript.

\section{Additional informations}

ORCID: Natan Feter (0000-0001-6295-9792); Jayne Santos Leite (0000-0002-4612-7301); Ricardo Alt (0000-0002-1704-5040); Airton José Rombaldi (0000-0002-6707-814X).

\section{Acknowledgments}

This study was financed in part by the Brazilian Graduate Studies Coordinating Board (CAPES; Finance Code 001).

\section{References}

1. GBD 2016 Dementia Collaborators. Global, regional, and national burden of Alzheimer's disease and other dementias, 1990-2016: a systematic analysis for the Global Burden of Disease Study 2016. Lancet Neurol 2019; 18:88-106.

2. Gianattasio KZ, Prather C, Glymour MM, Ciarleglio A, Power MC. Racial disparities and temporal trends in dementia misdiagnosis risk in the United States. Alzheimers Dement 2019; 5:891-8.

3. Instituto Brasileiro de Geografia e Estatística. Pesquisa Nacional por Amostra de Domicílios Contínua (PNAD Contínua). https:// www.ibge.gov.br/estatisticas/sociais/traba lho/9171-pesquisa-nacional-por-amostra-dedomicilios-continua-mensal.html (accessed on 29/Apr/2021).

4. Alzheimer's Association. 2020 Alzheimer's disease facts and figures. Alzheimers Dement 2020; 16:391-460.

5. Chin AL, Negash S, Hamilton R. Diversity and disparity in dementia: the impact of ethnoracial differences in Alzheimer's disease. Alzheimer Dis Assoc Disord 2011; 25:187-95.

6. Cooper C, Tandy AR, Balamurali TBS, Livingston $\mathrm{G}$. A systematic review and meta-analysis of ethnic differences in use of dementia treatment, care, and research. Am J Geriatr Psychiatry 2010; 18:193-203.

7. Regan JL. Ethnic minority, young onset, rare dementia type, depression: a case study of a Muslim male accessing UK dementia health and social care services. Dementia 2016; 15:702-20.

8. Nakamura AE, Opaleye D, Tani G, Ferri CP. Dementia underdiagnosis in Brazil. Lancet 2015; 385:418-9.

9. Feter N, Leite JS, Cardoso RK, Rombaldi AJ. Economic burden of physical inactivity in hospitalizations due to dementia: a Brazilian nationwide study. Cad Saúde Pública 2021; 37:e00046520.

10. Alzheimer's Disease International. World Alzheimer Report 2019: attitudes to dementia. https://www.alzint.org/resource/worldalzheimer-report-2019/ (accessed on 29/Apr/ 2021).

11. Mukadam N, Cooper C, Livingston G. A systematic review of ethnicity and pathways to care in dementia. Int J Geriatr Psychiatry 2011; 26:12-20.

12. Gray HL, Jimenez DE, Cucciare MA, Tong H-Q, Gallagher-Thompson D. Ethnic differences in beliefs regarding Alzheimer disease among dementia family caregivers. Am J Geriatr Psychiatry 2009; 17:925-33.

13. Babulal GM, Quiroz YT, Albensi BC, Arenaza-Urquijo E, Astell AJ, Babiloni C, et al. Perspectives on ethnic and racial disparities in Alzheimer's disease and related dementias: update and areas of immediate need. Alzheimers Dement 2019; 15:292-312. 
14. World Health Organization. Pulse survey on continuity of essential health services during the COVID-19 pandemic: interim report, 27 August 2020. Geneva: World Health Organization; 2020.

15. Nouri S, Khoong EC, Lyles CR, Karliner L. Addressing equity in telemedicine for chronic disease management during the Covid-19 pandemic. NEJM Catalyst Innovations in Care Delivery 2020; 1-13.

16. Ohannessian R, Duong TA, Odone A. Global telemedicine implementation and integration within health systems to fight the COVID-19 pandemic: a call to action. JMIR Public Health Surveill 2020; 6:e18810.

17. Krishnamoorthy G, Arsene C, Jena N, Mogulla SM, Coakley R, Khine J, et al. Racial disparities in COVID-19 hospitalizations do not lead to disparities in outcomes. Public Health 2020; 190:93-8.

18. Dong E, Du H, Gardner L. An interactive webbased dashboard to track COVID-19 in real time. Lancet Infect Dis 2020; 20:533-4.

19. Instituto Brasileiro de Geografia e Estatística. Continuous PNAD - Continuous National Household Sample Survey. https://www. ibge.gov.br/en/statistics/social/labor/16833monthly-dissemination-pnadc $1 . h t m l ?=\& \mathrm{t}=\mathrm{O}-$ que-e (accessed on 10/Mar/2020).

20. World Health Organization. ICD-10 : International Statistical Classification of Diseases and Related Health Problems. Tenth Revision. 2nd Ed. Geneva: World Health Organization; 2004.

21. Baqui P, Bica I, Marra V, Ercole A, van der Schaar M. Ethnic and regional variations in hospital mortality from COVID-19 in Brazil: a cross-sectional observational study. Lancet Glob Health 2020; 8:e1018-26.

22. van der Flier WM, Scheltens P. Epidemiology and risk factors of dementia. J Neurol Neurosurg Psychiatry 2005; 76 Suppl 5:v2-7.

23. Wang Q, Davis PB, Gurney ME, Xu R. COVID-19 and dementia: analyses of risk, disparity, and outcomes from electronic health records in the US. Alzheimers Dement 2021; 17:12971306.
24. Alzheimer's Association. 2014 Alzheimer's disease facts and figures. Alzheimers Dement 2014; 10:e47-92.

25. Rajan KB, Barnes LL, Wilson RS, McAninch EA, Weuve J, Sighoko D, et al. Racial differences in the association between apolipoprotein $\mathrm{E}$ risk alleles and overall and total cardiovascular mortality over 18 years. J Am Geriatr Soc 2017; 65:2425-30.

26. Barnes LL, Bennett DA. Alzheimer's disease in African Americans: risk factors and challenges for the future. Health Aff (Millwood) 2014; 33:580-6.

27. Helzner EP, Scarmeas N, Cosentino S, Tang MX, Schupf N, Stern Y. Survival in Alzheimer disease: a multiethnic, population-based study of incident cases. Neurology 2008; 71:1489-95.

28. Francisco PMSB, Segri NJ, Borim FSA, Malta DC. Prevalência simultânea de hipertensão e diabetes em idosos brasileiros: desigualdades individuais e contextuais. Ciênc Saúde Colet 2018; 23:3829-40.

29. Moraes FS, Souza MLC, Lucchetti G, Lucchetti ALG. Trends and disparities in the use of cholinesterase inhibitors to treat Alzheimer's disease dispensed by the Brazilian public health system - 2008 to 2014: a nation-wide analysis. Arq Neuropsiquiatr 2018; 76:444-51.

30. Alzheimer's Association. 2011 Alzheimer's disease facts and figures. Alzheimers Dement 2011; 7:208-44.

31. Alzheimer's Association. 2019 Alzheimer's disease facts and figures. Alzheimers Dement 2019; 15:321-87.

32. Souza RKM, Barboza AF, Gasperin G, Garcia HDBP, Barcellos PM, Nisihara R. Prevalence of dementia in patients seen at a private hospital in the Southern Region of Brazil. Einstein (São Paulo) 2020; 18:eAO4752. 


\section{Resumo}

O estudo teve como objetivo examinar o efeito da pandemia da COVID-19 sobre disparidades étnico-raciais nas hospitalizações e desfechos relacionados à demência no Brasil. Foi realizado um estudo de painel longitudinal com dados extraídos do Sistema de Informações Hospitalares do Sistema Único de Saúde (SIH/SUS). Avaliamos o número de internações hospitalares por 100 mil habitantes, média de gastos hospitalares e taxa de mortalidade por demência durante o primeiro semestre de 2019 e de 2020. Os dados foram estratificados por região geográfica e grupo étnico-racial (preto, pardo e branco) com base na cor da pele. Observamos uma redução geral nas internações, média de gastos hospitalares e taxa de mortalidade entre o primeiro semestre de 2019 e o mesmo período em 2020. Entretanto, as reduções nas taxas de hospitalização entre pretos e pardos foram 105,3\% e 121,1\% maiores que em brancos, respectivamente. A taxa de mortalidade diminuiu em $9 \%$ entre brancos e aumentou em $65 \%$ e $43 \%$ entre pretos e pardos, respectivamente. No primeiro semestre de 2020, pacientes pretos e pardos tiveram um risco mais alto de perder a vida por demência quando comparados aos brancos, disparidade essa não havia sido observada no mesmo período de 2019. Em 2020, a razão de mortalidade hospitalar atingiu os níveis mais altos em indivíduos pretos em todas as regiões exceto a Norte (dados não publicados). Desde o início da epidemia de COVID-19 no Brasil, aumentou a disparidade étnico-racial nas internações e taxas de mortalidade por demência. São necessárias medidas e políticas governamentais para mitigar esse efeito indireto da pandemia sobre a população brasileira.

Etnicidade; Demência; COVID-19

\section{Resumen}

El objetivo fue examinar el efecto de la pandemia de COVID-19 respecto a las disparidades étnicoraciales en hospitalizaciones, así como los resultados informados de las mismas, debido a la demencia en Brasil. Se trata de un estudio longitudinal en panel, realizado con datos extraídos del Sistema de Informaciones Hospitalarias del Sistema Único de Salud (SIH/SUS). Evaluamos el número de admisiones hospitalarias por 100.000 habitantes, la media del gasto hospitalario, además de la tasa de mortalidad hospitalaria, debido a la demencia, durante el primer semestre de 2019 y 2020. Los datos fueron estratificados por región geográfica y grupos étnico-raciales (negros, mestizos, y blancos), basados en su color de piel. Observamos en general una reducción en las admisiones hospitalarias, media del gasto hospitalario, y tasa de mortalidad entre el primer semestre de 2019 y 2020. No obstante, la reducción de las tasas de hospitalización entre negros y mestizos fue $105.3 \%$ y 121 .1\% superior, respecto a la de los blancos, respectivamente. La tasa de mortalidad decreció un $9 \%$ en blancos y aumentó en un 65\% y un $43 \%$ en la población negra y mestiza, comparativamente. En el primer semestre de 2020, los pacientes negros y mestizos tenían un riesgo más alto de fallecer, debido a la demencia que la gente blanca, esta disparidad no se observó en el mismo periodo de 2019. En 2020, la ratio de mortalidad hospitalaria alcanzó los valores más altos entre individuos negros en todas las regiones, salvo en el Norte (no habia datos disponibles). Desde el principio de la epidemia de COVID-19 en Brasil, la disparidad étnico-racial en las admisiones hospitalarias y tasas de mortalidad, debido a la demencia, se ha incrementado. Son urgentes acciones gubernamentales y politicas para mitigar este efecto indirecto de la pandemia en la población brasileña.

Etnicidad; Demencia; COVID-19
Submitted on $03 / \mathrm{Feb} / 2021$

Final version resubmitted on 06/May/2021

Approved on 14/May/2021 